\title{
Analysis of Vegetation Change and Mapping Tree Species in Mountainous Area Using Multi-Source Satellite Data: A Case Study of Djebel El Ouahch, Algeria
}

\author{
Mohamed Gana*, Azzedine Mohamed Toufik Arfa, Mohamed El Habib Benderradji, Djamel Alatou \\ Laboratory of Development and Valorisation of Phyto-Genetics Ressources, Department of Biology and Ecology, \\ University of Frères Mentouri Constantine, Algeria \\ *Corresponding author: gana.mohammed@umc.edu.dz
}

\begin{abstract}
Monitoring vegetation cover change and mapping the distribution of forest tree species has been considered as a key issue in sustainable development policies, the purpose of this research is to detect vegetation cover changes over 30 years (1987- 2016), and perform forest type classification by using Multi-Source Satellite Data and field survey investigations in the massive of Djebel El Ouahch. Algeria. The vegetation cover changes were quantified using Normalized Difference Vegetation Index (NDVI) combined with supervised classification methods, based on time series Landsat images. Furthermore, the dominant tree species in the wooded area was estimated using Google Earth imagery, the fieldwork was done simultaneously with a visual interpretation of Google Earth images, the thematic maps were prepared and accuracy assessment results are considered satisfactory. The results revealed that the cropland and non-vegetated areas have increased by $22 \%$, and $6.22 \%$ respectively. In contrast, significant spatial reduction in natural vegetation was observed. Both of Moderate and dense vegetation were decreased by $26.23 \%$ and $1.98 \%$, respectively, the current results play an important role in any planning process and indicating the necessity to create a new strategy based on protecting the natural vegetation and plants diversity.
\end{abstract}

Keywords: vegetation, NDVI, Djebel El Ouahch, tree species, mountainous

Cite This Article: Mohamed Gana, Azzedine Mohamed Toufik Arfa, Mohamed El Habib Benderradji, and Djamel Alatou, "Analysis of Vegetation Change and Mapping Tree Species in Mountainous Area Using Multi-Source Satellite Data: A Case Study of Djebel El Ouahch, Algeria.” American Journal of Environmental Protection, vol. 5, no. 2 (2017): 44-51. doi: 10.12691/env-5-2-3.

\section{Introduction}

In light of the recent ecological threats in developing countries, information on land cover change has been considered as an effective way for monitoring environmental quality, and dealing with the distribution of natural resources [1,2]. In the last decades, as the result of natural factors and human disturbances, the forest area has been decreased remarkably, particularly primary forest [3,4]; the loss of biodiversity has reached critical levels at different scales due to human activities such as: overexploitation of forest resources, forest fires, overgrazing, and destruction of habitats [5,6].

In Algeria, the natural vegetation in mountainous areas has been rapidly deteriorating, especially, during the last three decades. Developing concepts and tools to describe and quantify vegetation change and Provide timely information about forest resource, at regional and local scales, is necessary for addressing climate change, biodiversity, and other Ecological crisis's [3].
Covering north-eastern part of the Tell Atlas mountain range, the massive of Djebel El Ouahch includes the largest forest in the province of Constantine and extends over an area of 71522 hectares. Djebel El Ouahch is home to the largest community of stone pine forest in the county, and more than two thousand species which is considered one of the most important biological and ecological sites in Algeria. In that respect, spatial and temporal analysis of vegetation coverage change and mapping tree species in this area plays an important role for local and regional land managers and policy makers. Furthermore, the analysis of vegetation with remotely sensed data and GIS technology has become more reliable through time. However, the accuracy is generally determined by the spatial, spectral, radiometric and temporal resolutions which are available for each satellite data type [7].

Normalized Difference Vegetation Index (NDVI) is one of the most commonly indicators used to detect and analyse spatio-temporal changes of the vegetation cover by using Multi-spectral remote sensing data [8].NDVI is correlate with vegetation growth and photosynthetic activities based on the reflectance rates of the electromagnetic 
spectrum of chlorophyll pigments [9,10]. Furthermore, NDVI results can be employed to describe "change/no change” in vegetation cover by using NDVI differencing method [11].

On the other hand, tree species diversity is an important component for forest ecosystems research and offering the ability to provide valuable information about forest susceptibility to drought, pathogens and fires. Unfortunately, obtaining an accurate tree species classification from high floristic diversity, using Multispectral Landsat images, is still a challenging task, many factors influences the spectral response of tree species such as: leaf biochemical and physiological properties, canopy structure, density, age, and environmental conditions [12]. In that respect, Google Earth imagery, as a free and open source data, with spatial resolution less than $0.5 \mathrm{~m}$, have provided great supports for mapping the spatial distribution of tree species using the visual characteristics such as shape, texture, colour, size, pattern, site.... based on screen digitizing process and field trips, in ways that are actually very difficult for any algorithm $[13,14]$.

By consulting the published literature, most land cover studies examined the processes of desertification and land degradation over arid and semiarid areas using low and medium spatial resolution imagery, such as MODIS and Landsat data. Other works studied the vegetation cover change using Multispectral, Hyperspectral imagery, or orthophotography at local scales $[15,16]$. However, no previous work has been performed in the massive of Djebel El Ouahch, which have not received adequate attention to monitor patterns of vegetation change over the last 30 years and to assess the tree species diversity using multi-source satellite data approach.

With this background, the aims of this study are: (1) to investigate the use of NDVI as an indicator for assessing the vegetation cover change in Djebel El Ouahch based on three Landsat images, acquired on August 1987, June 2001 and August 2016; (2) to determine the shifts and quantify those changes by using post-classification technique; (3) mapping tree species by using Google Earth Imagery combined with fieldwork, and investigate the preliminary elements of vegetation Changes.

\section{Materials and Methods}

\subsection{The Study Area}

The present study has been carried out on the massive of Djebel El Ouahch in north-east of Algeria. The studied area is located between $36^{\circ} 13^{\prime} 58^{\prime \prime} \mathrm{N}$ and $36^{\circ} 33^{\prime} 54^{\prime \prime} \mathrm{N}$ latitudes and 6 ${ }^{\circ} 38^{\prime} 03^{\prime \prime} \mathrm{E}$ and $6^{\circ} 59^{\prime} 46.48 " \mathrm{E}$ longitudes (Figure 1), at altitudes ranging from 285 to $1343 \mathrm{~m}$ above sea level, and extends over 71522 hectares. Djebel El Ouahch is dominated by a mountainous area to the east, which is an extension of Tell chain; the highest elevation is the mount Shagref (1343 m above sea level), while the high plains are located in the south, the landscape heterogeneity provides a large area under Agro-SilvoPastoral system.

The natural vegetation in the study area varies from coniferous woodland to deciduous woodland, shrubland and grassland. The major associated species are: stone pine (Pinus pinea), Aleppo pine (Pinus halepensis), cork oak (Quercus suber), Eucalyptus, and evergreen oak (Quercus ilex).

Djebel El Ouahch has a Mediterranean climate with hot, dry summers and moist, mild winters. The highest temperatures usually occur in the period from June to August with an average maximum temperature range from 27 to $33{ }^{\circ} \mathrm{C}$. The period from December to February is considered to be a cool season, with a mean temperature of 6 to $8^{\circ} \mathrm{C}$. The area receives a mean annual rainfall ranging from $600 \mathrm{~mm}$ to $900 \mathrm{~mm}$ and is distributed from November to April. The rainfall patterns are highly variable in time and space.

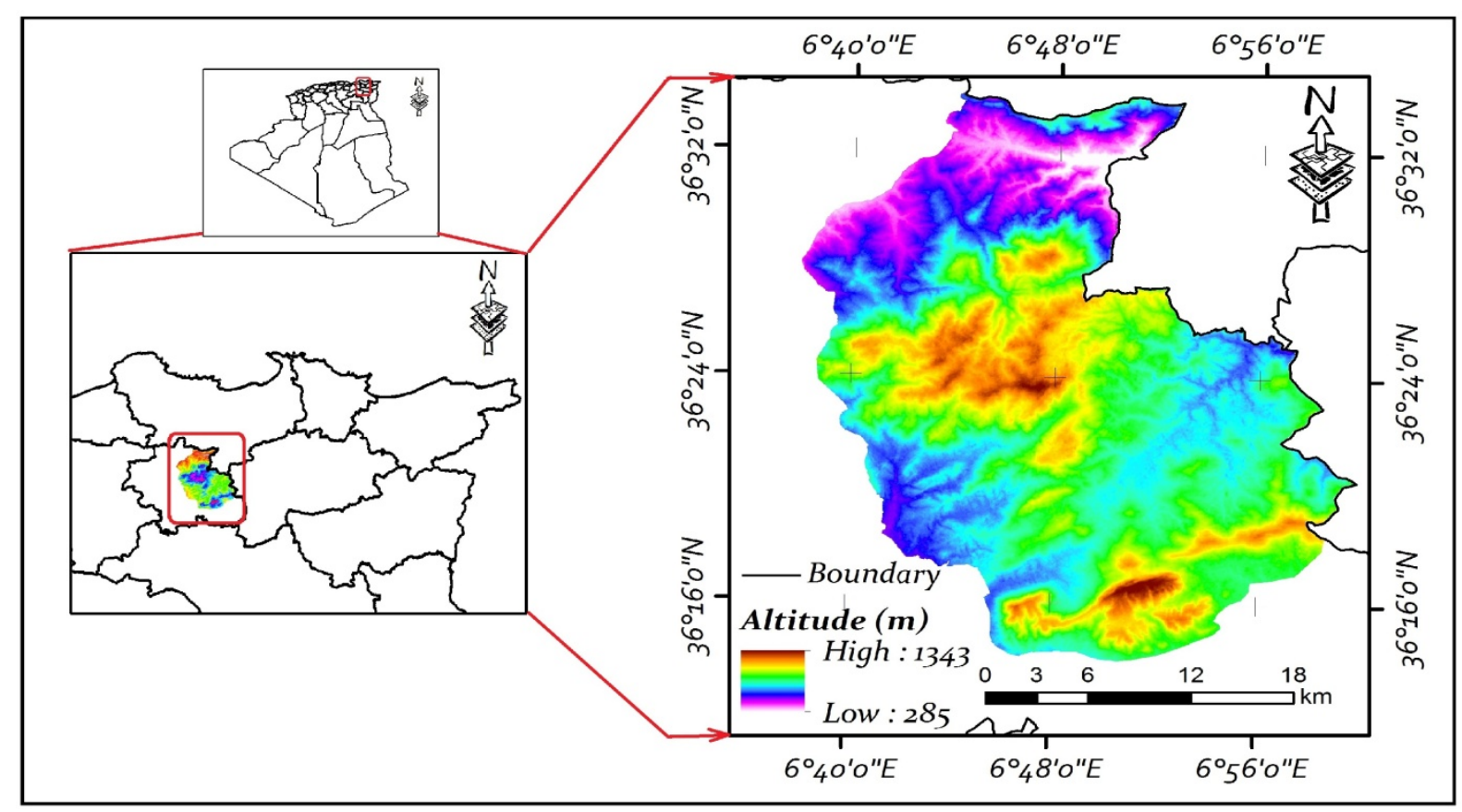

Figure 1. Location of the study area (Elevation source: ASTER GDEM version 2) 


\subsection{Data Sources}

For the purpose of determining vegetation cover change in the study area through time, Landsat satellite data was used, which are available from United States Geological Survey (USGS) website (http://earthexplorer.usgs.gov/).

From the available Landsat archive data, three scenes covering the study area (Path 193/Row 35) were obtained on 03 August 1987 (Landsat 4-5 TM), 30 June 2001 (Landsat 7 ETM+) and 08 August 2016 (Landsat 8 OLI). They were acquired during the dry season, to reduce variations in solar elevation angles, and minimize the possible occurrence of change in environmental conditions.

For more efficiency, other spatial data were collected and produced: Aerial photography acquired in 1987, topographic maps, high resolution imagery of Google Earth, Digital Elevation Model (DEM), and data from fieldwork were used as reference data for land cover Classification, producing the vegetation maps, and also for the accuracy assessment.

\subsection{NDVI and NDVI Differencing}

Vegetation indices have been used extensively as an indicator to quantify the greenness of plants and monitoring multi-temporal changes of vegetation within satellite data [17]. There are several vegetation indices such as: Perpendicular Vegetation Index (PIV), Ratio Vegetation Index (RVI), Normalized Difference Vegetation Index (NDVI), Soil Adjusted Vegetation Index (SAVI), However, NDVI is generally proven as The best indicator of vegetation growth and photosynthetic activities, also, It can be used for monitoring land cover changes and generate vegetation maps over time, which is considered to be one of the most frequently used vegetation index for vegetation studies [18]. The NDVI layer is defined as:

$$
\mathrm{NDVI}=(\mathrm{NIR}-\mathrm{R}) /(\mathrm{NIR}+\mathrm{R}),
$$

Where: NIR and $\mathrm{R}$ represents the spectral reflectance measurements acquired in the red $(\mathrm{R})$ and near-infrared (NIR) bands, the result of this algorithm is a single data band with NDVI values ranging from -1 to $1[19,20]$, where values near 1 indicate increasing green vegetation cover, and negative values indicate non-vegetated features such as barren land and water body.

In order to quantify the Vegetation Change, NDVI differencing was applied, this technique is based on subtracting the NDVI values of the different time periods at the same location to create the difference image. It is the most frequently used technique in change detection studies, especially, when "vegetated/ none vegetated" areas are the subject of this changes [21]. NDVI Differencing is defined as:

$$
\text { NDVI Differencing = NDVI (T1) - NVDI (T2). }
$$

In the first stage, NDVI data layers were generated for each dates, then, NDVI differencing was calculated to identify the pixel changes/ pixel not changes by subtracting NDVI values between two dates for each image pairs (NDVI in 1987 from NDVI in 2001; NDVI in 2001 from NDVI in 2016; NDVI in 1987 from NDVI in 2016) and finally, The change/ no change maps were generated using an appropriate threshold, the negative and Positive change in digital number which are bigger than the given threshold was considered as area of change. While, the negative and positive change smaller than the given threshold were considered as no change, the best threshold used for classification is chosen based on known ground data and using ENVI 5.1 software,

\subsection{Image Classification and Accuracy Assessment}

Based on the information revealed by NDVI Differencing technique, supervised classification was employed to classify each image independently using the maximum likelihood classifier (MLC). MLC estimate the probability of a pixel belonging to each of a predefined set of classes, and then allocates each pixel in the appropriate class with high reliability [22], MLC algorithm requires training areas to create spectral signatures from imageries. More than 140 Region of Interest (ROI), or training sites, were selected from the whole study area based on Google Earth imagery, topographic maps, and field visits. Moreover, unified distributed training sites for all images to ensure that the classification for the three dates images is compatible to each other [23]. Then, maximum likelihood classifier was performed to generate land cover maps with four (04) classes: (1) Dense vegetation; (2) Moderate vegetation; (3) Cropland, and (4) No vegetation. The classification results were also evaluated using accuracy assessment, In order to determine the accuracy assessment of land cover maps, more than 200 random points were generated for each map to build confusion matrix. The aerial photography (1:10.000) acquired in 1987 were used as reference data for 1987 classified map, while the combination of topographic maps (1:25.000), Google Earth, and fieldwork data were used as reference for 2001 and 2016 classified maps. Then, error matrix compares information from the classified map to the reference data. User's accuracy, producer's accuracy, Overall accuracy, and kappa statistics were calculated for each land cover map.

\subsection{Change Detection Analysis}

Change detection is the operation of identifying the transition between initial and final state refers to observing phenomenon at different times [24]. Change detection is performed not only to detect where changes occurred, but also to identify the pattern and magnitude of those changes by comparing the classified data at different times [25]. In order to estimate the rate of conversions from land cover category to another and their corresponding area over the evaluated period, post-classification change detection approach was conducted based on pairwise comparison of two maps. The output table of changes can be reported as percentages, surface areas, or pixels counts.

\section{Results and discussion}

\subsection{NDVI Results}

In the first part of the results, The NDVI layers for all images were colored to examine the distribution of vegetation cover over the whole study area at each date (Figure 2). Based on the information provided by 
elevation maps extracted from digital elevation model (Figure 1), the NDVI values were highly variable across the range of elevation, the highest NDVI values are found in majority at regions with (1300-950 m) elevation, indicating high density of vegetation cover with good condition, NDVI values from $(0.40-0.20)$ were found in regions with (950-800 m) elevation and indicating regions with moderate vegetation cover, Also, NDVI values from (0.2-0.05) are frequently located at regions of (800-300 m) which indicating croplands. Other areas recorded low NDVI values $(<0.05)$ and found in all sections which indicating non vegetated areas, including: built-up, water body, rocks, these facts were further established based on our Fieldwork data.

In the second stage, NDVI Differencing data layers were generated for each image pairs to identify the pixel changes/ pixel not changes by subtracting NDVI values between two dates, and the results can be clearly seen in (Figure 3), the changed areas are assigned red and blue colors, where red and blue represent lost and gain in vegetation areas, respectively, while regions with slight or no changes are shown in black.

\subsection{Vegetation Maps and Accuracy Assessment}

The classification system developed for vegetation cover in the study area was divided into four main classes: Dense vegetation, Moderate vegetation, Cropland, and No vegetation, the classified maps of Djebel El Ouahch for 1987, 2001 and 2016 images were obtained after preprocessing and supervised maximum likelihood classifier (Figure 4). Moreover, the surface area of each class was estimated (Table 2). The accuracy assessment process was done using confusion matrix for all land cover maps. The overall accuracy of TM 1987, ETM+ 2001, and OLI 2016 images was $83.6 \%, 84.49 \%$, and $85.11 \%$ with corresponding kappa coefficients of $78.15 \%, 79.31 \%$, and $79.99 \%$ respectively. Furthermore, user's and producer's accuracy were also computed for each land cover maps (Table 2).

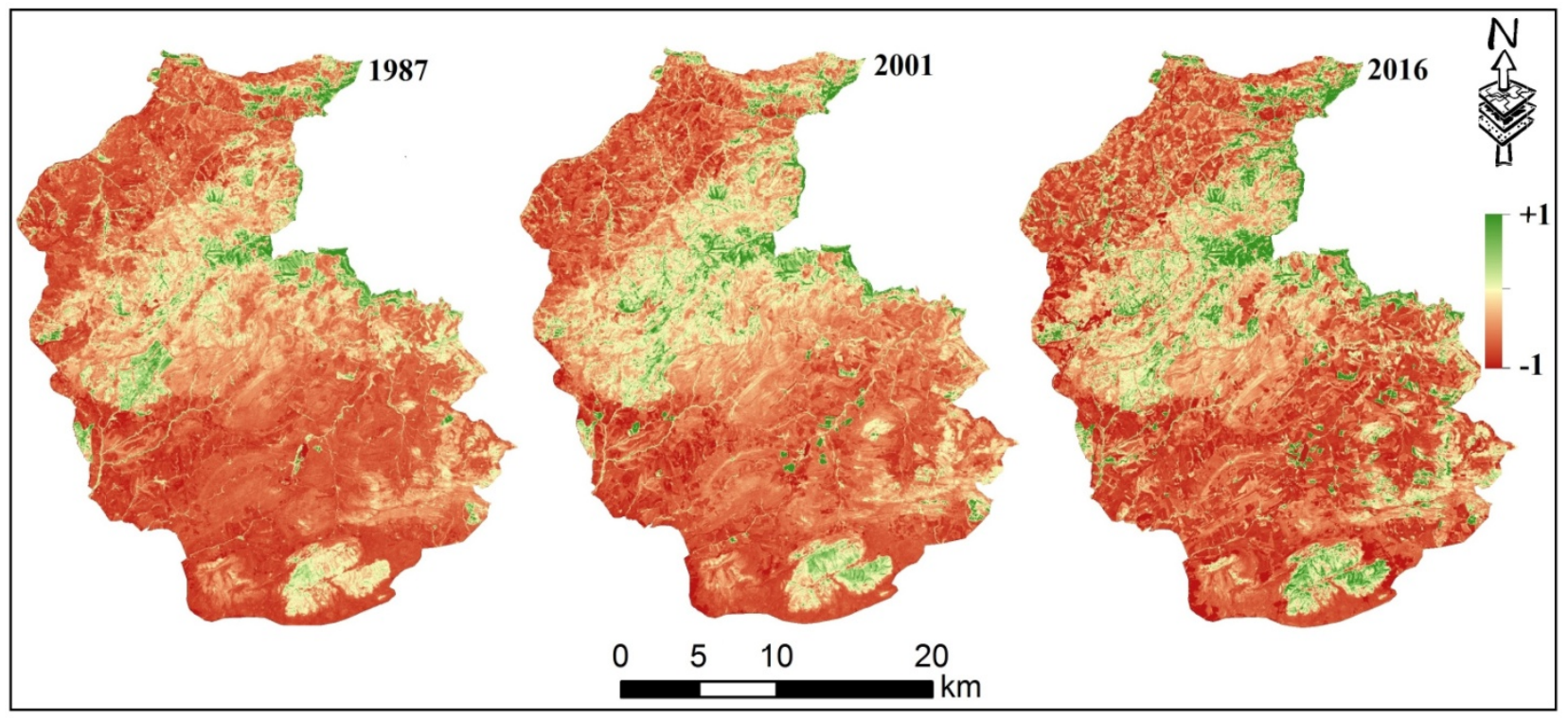

Figure 2. NDVI Maps of Djebel El Ouahch in 1987, 2001 and 2016

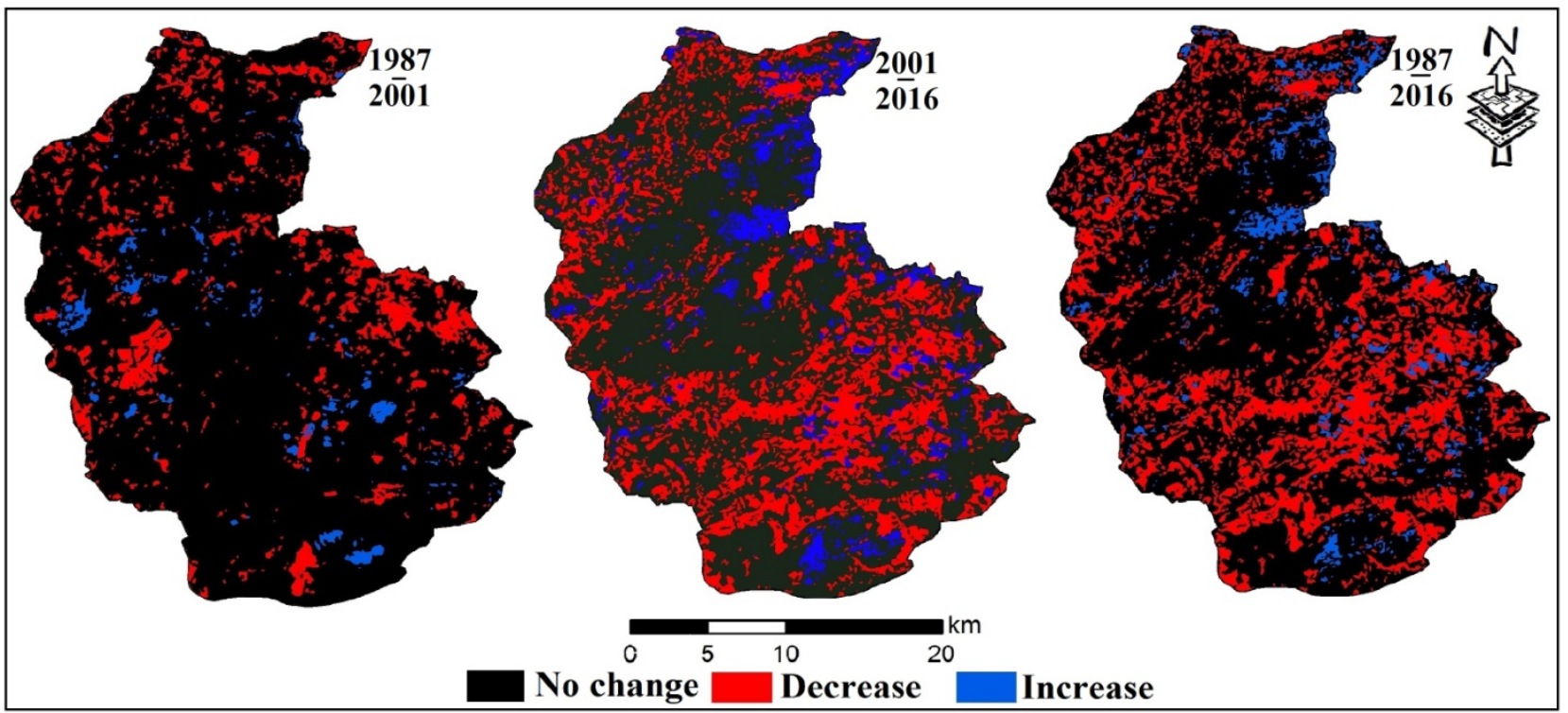

Figure 3. Change/ No change maps between 1987-2001, 2001-2016, and 1987-2016 


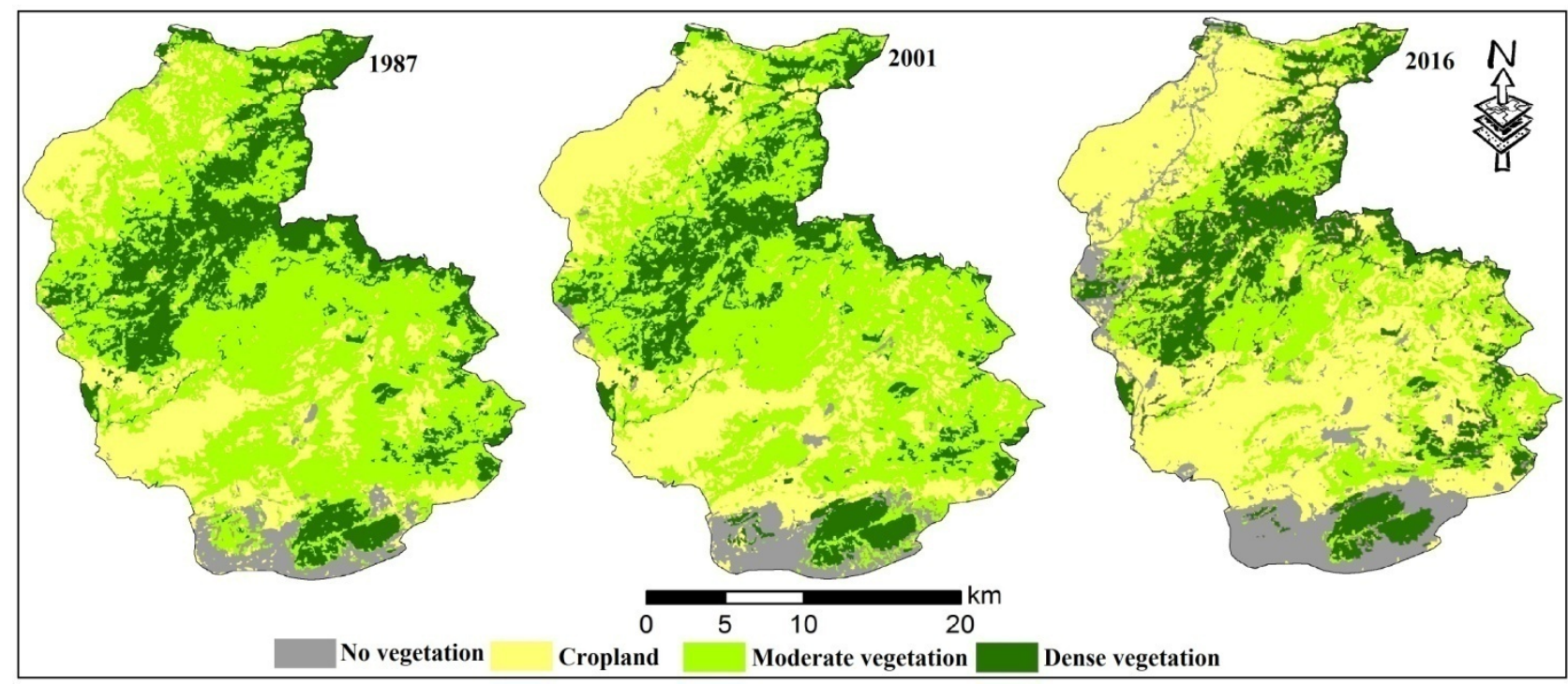

Figure 4. Vegetation Maps for Djebel El Ouahch Massive in 1987, 2001, and 2016

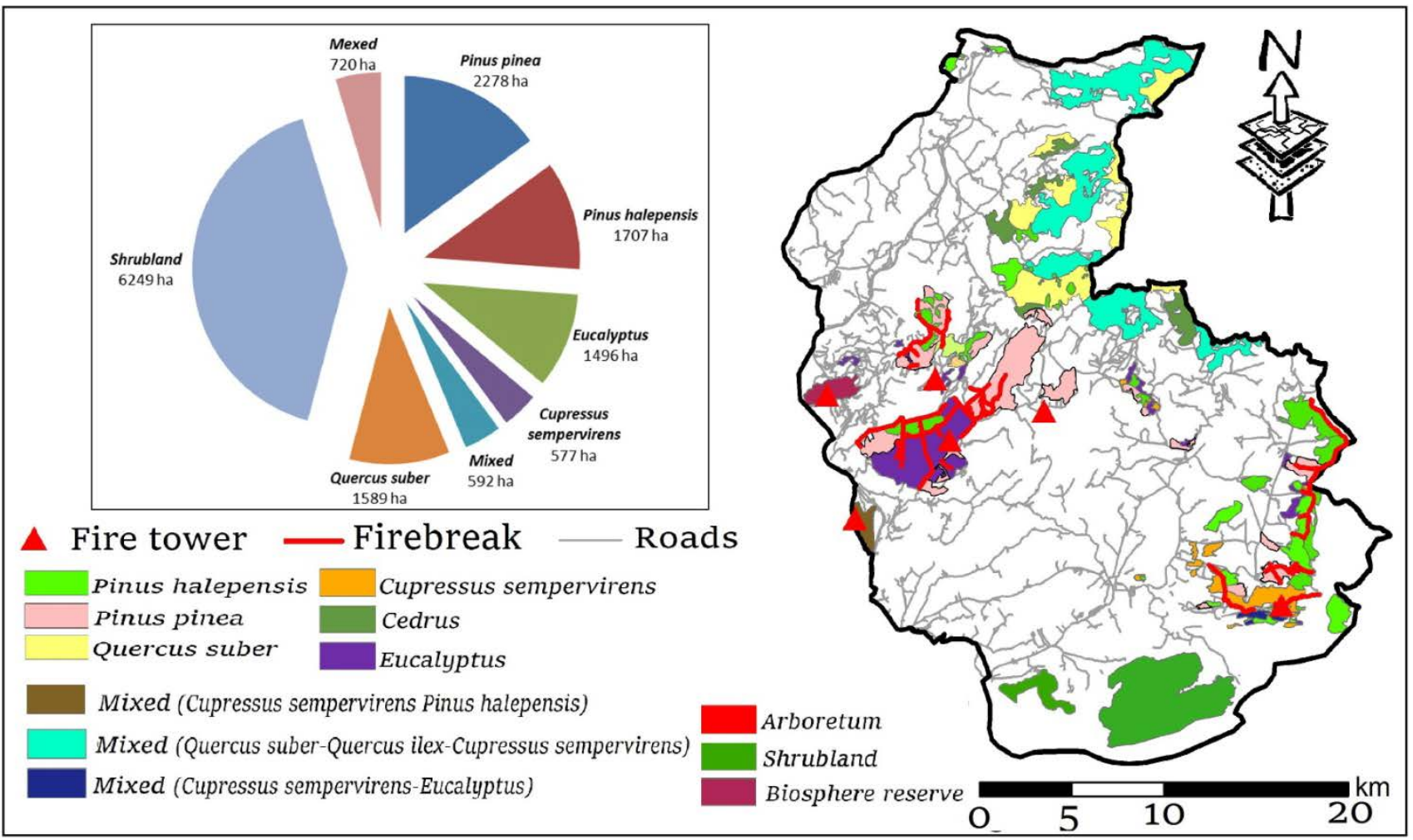

Figure 5. Forest cover types distribution in Djebel El Ouahch

The high resolution images of Google Earth had also a great supports to assess tree species diversity based on screen digitizing process and fieldwork in such a way that forest type groups and infrastructure are easily recognized. As shown in Figure 5, the major forest types and tree communities in Djebel El Ouahch was carried out, the results indicate that, cork oak (Quercus suber); stone pine (Pinus pinea); and evergreen oak (Quercus ilex), cover most of the natural forest area and frequently found in the north and extends over 1598 ha, 2278 ha and 592 ha respectively, However, the coverage of the plantations forestry such as Aleppo pine (Pinus halepensis) and Eucalyptus communities are located to the south and extends over 1707 ha and 1496 ha respectively (Figure 5), these variations are related to soil properties, topographic, climatic, and socioeconomic factors.

\subsection{Change Detection Analysis}

The results obtained through the analysis of NDVI and classified maps, illustrate a substantial change in vegetation over time, and provide valuable information about land cover pattern in Djebel el Ouahch. There is no doubt that the socioeconomic factors are the major cause of vegetation change during the past three decades. In order to estimate the rate of conversions from land cover class to another over the evaluated period, post- classification technique was conducted. A spatio-temporal quantification 
and graphical representation of the different changes in vegetation cover for 1987, 2001, and 2016 are demonstrated in (Table 1), (Table 3) and (Figure 5),

The results indicate that Dense vegetation area has decreased substantially from 15524 ha in 1987 to 12977 ha in 2001. It retained approximately 79.61\%, and the rest was mainly converted to Moderate vegetation 19.33\% (3002 ha) and Cropland 1.03\% (22 ha).at the same time, the Moderate vegetation class retained 27574 ha (74.59\%) from 33759 ha in 1987. It was reduced by $4.48 \%$ in 2001,

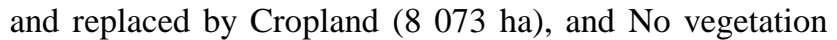
(709 ha). However, the changes from 2001-2016 include gain of Cropland (14.86\%), Dense vegetation (1.58\%), and No vegetation (5.3\%), and loss of Moderate vegetation by (21.74\%), Out of the 33759 ha that was Moderate vegetation area in 2001, (50.78\%) was still in the same class in 2016 , but 12.259 ha (36.31\%) was converted to Cropland, 2146 ha $(6.35 \%)$ to No vegetation, and the rest to Dense vegetation (6.53\%).

The examination of the entire study period, 1987 - 2016, at once, indicates that (63.21\%) of the total area of Djebel El Ouahch remained unchanged, while (36.78\%) underwent conversion between the land cover categories; the increase of Cropland area was mainly from natural vegetation, and new cultivated land were created at the expense of Moderate vegetation (16 565 ha) and Dense vegetation (1 015 ha) which experienced significant reduction over the past 30 years by $26.23 \%$ and $1.98 \%$, respectively.

Table 1. Summary of vegetation change statistics from (1987- 2016)

\begin{tabular}{|c|c|c|c|c|c|c|c|c|c|c|c|c|}
\hline \multirow{2}{*}{ Land Cover Classes } & \multicolumn{2}{|c|}{$\underline{1987}$} & \multicolumn{2}{|c|}{$\underline{2001}$} & \multicolumn{2}{|c|}{$\underline{2016}$} & \multicolumn{2}{|c|}{$\begin{array}{c}\text { Area changed } \\
1987-2001 \\
\end{array}$} & \multicolumn{2}{|c|}{$\begin{array}{c}\text { Area changed } \\
2001-2016 \\
\end{array}$} & \multicolumn{2}{|c|}{$\begin{array}{c}\text { Area changed } \\
1987-2016 \\
\end{array}$} \\
\hline & (ha) & $\%$ & (ha) & $\%$ & (ha) & $\%$ & (ha) & $\%$ & (ha) & $\%$ & (ha) & $\%$ \\
\hline No vegetation & 2968 & 4.15 & 3624 & 5.07 & 7414 & 10.37 & 656 & 0,92 & 3790 & 5.30 & 4447 & 6.22 \\
\hline Cropland & 16064 & 22.46 & 21161 & 29.59 & 31792 & 44.45 & 5097 & 7.13 & 10630 & 14.86 & 15728 & 21.99 \\
\hline Moderate vegetation & 36966 & 51.69 & 33759 & 47.20 & 18209 & 25.46 & -3207 & -4.48 & -15550 & -21.74 & -18757 & -26.23 \\
\hline Dense vegetation & 15524 & 21.70 & 12977 & 18.14 & 14107 & 19.72 & -2547 & -3.56 & 1129 & 1.58 & -1417 & -1.98 \\
\hline
\end{tabular}

Table 2. The accuracy assessments of vegetation cover maps in 1987, 2001, and 2016

\begin{tabular}{|l|c|c|c|c|c|c|}
\hline \multirow{2}{*}{ Land cover classes } & \multicolumn{2}{|c|}{1987} & \multicolumn{2}{c|}{2001} & \multicolumn{2}{c|}{2016} \\
\cline { 2 - 8 } & User's (\%) & Producer's (\%) & User's (\%) & Producer's (\%) & User's (\%) & Producer's (\%) \\
\hline Dense Vegetation & 0.83 & 0.89 & 0.87 & 0.89 & 0.86 & 0.87 \\
\hline Moderate Vegetation & 0.82 & 0.72 & 0.84 & 0.79 & 0.84 & 0.78 \\
\hline Cropland & 0.83 & 0.81 & 0.79 & 0.77 & 0.80 & 0.80 \\
\hline No Vegetation & 0.84 & 0.93 & 0.86 & 0.93 & 0.87 & 0.94 \\
\hline Overall accuracy & \multicolumn{3}{|c|}{$\mathbf{8 3 . 6 0}$} & & $\mathbf{8 4 . 4 9}$ & \multicolumn{2}{|c|}{$\mathbf{8 5 . 1 1}$} \\
\hline Kappa statistics & \multicolumn{3}{|c|}{$\mathbf{7 8 . 1 5}$} & $\mathbf{7 9 . 3 1}$ & \multicolumn{2}{c|}{} \\
\hline
\end{tabular}

Table 3. Vegetation cover change matrix during 1987, 2001, and 2016 (ha)

\begin{tabular}{|c|c|c|c|c|c|c|}
\hline \multirow{2}{*}{\multicolumn{2}{|c|}{$\begin{array}{c}\text { Period } \\
\underline{1987-2001} \\
\end{array}$}} & \multicolumn{5}{|c|}{ Year 1987} \\
\hline & & No.V & Crp & Mod.V & Den.V & Total 2001 \\
\hline \multirow{5}{*}{ 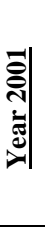 } & No.V & 2326 & 587 & 709 & 2 & 3624 \\
\hline & Crp & 228 & 12699 & 8073 & 161 & 21161 \\
\hline & Mod.V & 406 & 2778 & 27574 & 3002 & 33759 \\
\hline & Den.V & 8 & 0 & 610 & 12359 & 12977 \\
\hline & Total 1987 & 2968 & 16064 & 36966 & 15524 & 71522 \\
\hline \multicolumn{2}{|c|}{ Period } & \multicolumn{5}{|c|}{ Year 2001} \\
\hline \multirow{6}{*}{ 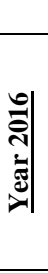 } & 2016 & No.V & Crp & Mod.V & Den.V & Total 2016 \\
\hline & No.V & 3407 & 1490 & 2147 & 370 & 7414 \\
\hline & Crp & 130 & 18719 & 12259 & 684 & 31792 \\
\hline & Mod.V & 83 & 953 & 17146 & 27 & 18209 \\
\hline & Den.V & 4 & 0 & 2207 & 11896 & 14107 \\
\hline & Total 2001 & 3624 & 21161 & 33759 & 12977 & 71522 \\
\hline \multicolumn{2}{|c|}{ Period } & \multicolumn{5}{|c|}{ Year 1987} \\
\hline \multicolumn{2}{|c|}{$\underline{1987-2016}$} & No.V & Crp & Mod.V & Den.V & Total 2016 \\
\hline \multirow{5}{*}{ 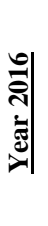 } & No.V & 2807 & 1408 & 2917 & 283 & 7414 \\
\hline & Crp & 133 & 14078 & 16565 & 1015 & 31792 \\
\hline & Mod.V & 25 & 534 & 15875 & 1775 & 18209 \\
\hline & Den.V & 2 & 44 & 1610 & 12451 & 14107 \\
\hline & Total 1987 & 2968 & 16064 & 36966 & 15524 & 71522 \\
\hline
\end{tabular}

No.V: No Vegetation; Crp: Cropland; Mod.V: Moderate Vegetation; Den.V: Dense Vegetation 
Table 4. The major tree species affected by forest fire (ha) in Djebel El Ouahch from 1987-2015. (Source: Forest Conservation Department)

\begin{tabular}{|l|c|c|c|}
\hline Forest cover types & $\mathbf{1 9 8 7 - 2 0 0 2}$ & $\mathbf{2 0 0 2} \mathbf{2 0 1 5}$ & $\mathbf{1 9 8 7 - 2 0 1 5}$ \\
\hline Quercus suber & 252 & 384 & 636 \\
\hline Cupressus sempervirens & 94 & 611 & 705 \\
\hline Eucalyptus & 46 & 299,5 & 345,5 \\
\hline Shrubland & 0 & 129,5 & 129,5 \\
\hline Mixed & 2,5 & 27,5 & 30 \\
\hline Pinus halepensis & 312,5 & 13 33,5 & 1646 \\
\hline Pinus pinea & 354 & 474,5 & 828,6 \\
\hline Biosphere reserve & 3 & 0,9 & 3,9 \\
\hline Total area & $\mathbf{1 0 6 4}$ & $\mathbf{3 2 5 9 , 5}$ & $\mathbf{4 3 2 4}$ \\
\hline Average rate/ year & $\mathbf{7 0 , 9 3}$ & $\mathbf{2 3 2 . 8 2}$ & $\mathbf{1 4 9 , 1}$ \\
\hline
\end{tabular}

According to Forest Conservation Department, forest fires, deforestation for agricultural expansion, over grazing, cutting of fuel wood by the local communities, mismanagement and forest diseases plays an important role in vegetation decline; more than 4300 hectares of forest land were significantly affected by fire from 1987 to 2015, particularly in summer, with an average rate of 149 ha each year (Table 4). In addition to forest fires, Moderate vegetation was also triggered by various factors that undermine the sustainable potential of these lands. About $57 \%$ of Moderate vegetation class has been converted to other uses, especially cropland, due to population growth and new resettlement and development programs designed for enhancing food security, by strengthening agricultural investments and financial services to expand and reclaim farmland and improving agricultural performance. However, this kind of practices could make the natural vegetation vulnerable and influence the forest ability to regenerate.

\section{Conclusion}

In this study, we attempted to detect vegetation cover change in the mountainous areas of Djebel el Ouahch between 1987 and 2016 using Multi-temporal Landsat images, ancillary data and fieldwork. A combination of NDVI differencing method and supervised classification techniques were employed to generate different maps for each observation dates with (04) major classes: Dense vegetation, Moderate vegetation, Cropland, and No vegetation, the accuracy assessment was tested and the results are considered satisfactory.

The vegetated area is mostly located in the regions with 900-1300 m elevation. While the majority of land farmed is concentrated in the high plans, however, as the result of natural factors and human disturbances, the vegetation patterns in the massive of Djebel el Ouahch has been changed during the last 30 years, especially, the dramatic decline in vegetation cover over time. The distributions of NDVI and classified maps for period 1987, 2001, and 2016 showed positive pattern of Cropland and Non-vegetated area and negative pattern of Dense and Moderate vegetation due to human activities such as: overexploitation of forest resources, forest fires, farmland expansion strategy, and overgrazing.
Finally, it seems necessary to conduct more research in this area, at a local scale, to minimize the impact of these changes, in order to insure the sustainability of the natural environment, and reduce the risks associated with land use dynamics aver time.

\section{Acknowledgements}

This work was supported by the Forest Conservation Department. We thank Mr. Houssine Majdoub, Mr. Mohamed Saighi, and Mr. Bouzide Mesbahi for their valuable assistance during the fieldwork. We are also grateful to anonymous reviewers for their comments and constructive criticisms.

\section{References}

[1] Wentz, E., D. Nelson, A., Rahman, W. Stefanov, W., and Roy, S, "Expert system classification of urban land use/cover for Delhi, India," International Journal of Remote Sensing, 29 (15). 4405-4427. 2008.

[2] Olaleye J.B, "Land-use and land-cover analysis of Ilorin Emirate between 1986 and 2006 using landsat imageries," African Journal of Environmental Science and Technology, 6 (4). 189-198. 2012.

[3] FAO, Global Forest Resources Assessment 2005: Progress Towards Sustainable Forest Management. Forest Resources Assessment (FRA) Report. FAO Forestry Paper 147 (Rome: Food and Agriculture Organization). 2006,

[4] FAO, State of the World's Forest 2007 (Rome: Food and Agriculture Organization).2007.

[5] Fischer, J., and Lindenmayer, D.B, "Landscape modification and habitat fragmentation: a synthesis," Global Ecology and Biogeography, 16 (3). 265-280. 2007.

[6] Rahman, M.M., Ainun, N., and Vacik, H, "Anthropogenic disturbances and plant diversity of the Madhupur Sal forests (Shorea robusta C.F. Gaertn.) of Bangladesh,” International Journal of Biodiversity Science, Ecosystem Services \& Management, 5 (3). 162-173. 2009.

[7] Tonye, E., and Akono, A, le traitement des images de télédétection par l'exemple. Paris: Edit. Gordon and Breach, 2000.

[8] Nath, B, "Quantitative Assessment of Forest Cover Change of a Part of Bandarban Hill Tracts Using NDVI Techniques," Journal of Geosciences and Geomatics, 2 (1). 21-27. 2014.

[9] Sellers, P.J, "Canopy reflectance, photosynthesis and transpiration," International Journal of Remote Sensing, 6 (8). 1335-1372. 1985

[10] Campbell, J.B, Introduction to remote sensing, CRC Press, 2002.

[11] Mishra, S., Shrivastava, P., and Dhurvey, P, "Change Detection Techniques in Remote Sensing," Journal Of Advanced Information Technology And Convergence, 6 (2). 51. 2016

[12] Sheeren, D., Fauvel, M., Josipović, V., Lopes, M., Planque, C., Willm, J., and Dejoux, J, "Tree Species Classification in Temperate Forests Using Formosat-2 Satellite Image Time Series," Remote Sensing, 8 (9). 734. 2016.

[13] Joseph, G, Data Analysis. In: Joseph G (ed) Fundamentals of remote sensing, 2nd ed, Universities Press, India, 2005, 319-348.

[14] Mering, C., Baro, J., and Upegui, E, "Retrieving urban areas on Google Earth images: application to towns of West Africa," International Journal of Remote Sensing, 31 (22). 5867-5877. 2010.

[15] Hirche, A., Salamani, M., Abdellaoui, A., Benhouhou, S., and Valderrama, J, "Landscape changes of desertification in arid areas: the case of south-west Algeria," Environmental Monitoring and Assessment, 179 (1-4). 403-420. 2010.

[16] Saädi, S., and Gintzburger, G, "A spatial desertification indicator for Mediterranean arid rangelands: a case study in Algeria," The Rangeland Journal, 35 (1). 47. 2013.

[17] Yacouba, D., Guangdao, H., and Xingping, W, “Assessment of Land Use Cover Changes Using NDVI and DEM in Puer and Simao Counties, Yunnan Province, China.” World Rural Observations, 1 (2). 1-11. 2009. 
[18] Panda, S.S., Ames, D.P., Panigrahi, S, “Application of vegetation indices for agricultural crop yield prediction using neural network techniques," Remote Sensing, 2 (3). 673-696. 2010.

[19] Sabins, F.F, Remote sensing, principles and interpretation. Third edition, H. Freeman and Company, New York, 1997.

[20] Jensen, J.R, Remote sensing of environment: an earth resource prospective. Prentice Hall, upper saddle River.N.J, UAS, 2000.

[21] Pu, R., Gong, P., Tian, Y., Miao, X., Carruthers, R.I., and Anderson, G.L, "Using classification and NDVI differencing methods for monitoring sparse vegetation coverage: a case study of saltcedar in Nevada, USA," International Journal of Remote Sensing, 29 (14). 3987-4011. 2008
[22] Tso, B., and Mather, P, Classification methods for remotely sensed data. 1st ed. Boca Raton, Fla.: CRC/Taylor \& Francis, 2009.

[23] Zhou, Q., Li, B., Kurban, A, "Trajectory analysis of land cover change in arid environment of China," International Journal of Remote Sensing, 29 (4). 1093-1107. 2008.

[24] Shah-Hosseini, R., Homayouni, S., and Safari. A, "A Hybrid Kernel-Based Change Detection Method for Remotely Sensed Data in a Similarity Space," Remote Sensing, 7 (10). 12829-12858. 2015

[25] Molina, I., Martinez, E., Morillo, C., Velasco, J., and Jara, A, "Assessment of Data Fusion Algorithms for Earth Observation Change Detection Processes." Sensors, 16 (10).1621. 2016 